DOI 10. 18307/2018. 0506

(c) 2018 by Journal of Lake Sciences

\title{
基于生态一社会服务功能协调发展度的湖泊健康评价方法”
}

\author{
㚞贤璐,徐国宾** \\ (天津大学水利工程仿真与安全国家重点实验室, 天津 300354)
}

\begin{abstract}
摘 要: 本文首先运用频度分析法构建湖泊生态系统健康评价指标体系; 其次,应用变异系数法与信息熵权法相结合的 组合赋权法计算指标权重; 在此基础上提出了基于生态一社会服务功能协调发展度的湖泊生态系统健康评价方法, 并给 出从湖泊综合发展水平和湖泊协调发展度两方面度量湖泊生态系统健康水平的等级划分标准. 应用此评价方法, 以白洋 淀生态系统为研究对象, 开展其健康状况及协调发展状况的模型实证研究. 结果显示: 白洋淀生态系统综合发展水平处 于不健康病态萎缩状态, 湖泊协调发展度属于临界协调发展. 该方法综合考虑了生态完整性和社会服务功能两个方面的 协调性和发展性进行湖泊健康评价, 从协调、发展的角度为湖泊管理建设提供建议. 同时研究表明协调发展度湖泊健康 评价法具有计算简单、适用性强的特点, 同样适用于其他湖泊健康评价.
\end{abstract}

关键词: 湖泊健康; 指标体系;组合赋权法;协调发展度; 白洋淀

\section{Lake health assessment method based on the coordinated development degree of ecology and social service function}

\author{
FAN Xianlu \& XU Guobin ** \\ ( State Key Laboratory of Hydraulic Engineering Simulation and Safety, Tianjin University, Tianjin 300354, P.R.China)
}

\begin{abstract}
In this paper, the lake ecosystem health evaluation index system was established using the frequency analysis method. Then, the weights of the index were calculated by the Combination Assigning Method combined Variation Coefficient Method with the Information Entropy Weight Method. Finally, the evaluation method of the lake ecosystem health was proposed based on the coordinated development degree of ecological-social service function. In addition, the classification standard of the lake ecosystem health level was given out from the aspects of lake comprehensive development level and lake coordinated development degree. Based on this evaluation method, Lake Baiyangdian ecosystem was used as the research object to carry out the empirical study on the health status and the coordinated development degree. The results show that the comprehensive development level of Lake Baiyangdian ecosystem is in the state of unhealthy morbid state, and the coordinated development degree belongs to the critical coordinated development. This method takes the coordination and development of ecological integrity and social service function into consideration while evaluating lake health, and provides suggestions for lake management construction from the point view of coordination and development.
\end{abstract}

Keywords: Lake health; index system; combination assigning method; coordinated development degree; Lake Baiyangdian

在可持续发展思想的推动下, “生态系统健康”已逐渐成为生态环境系统研究的热点问题之一. 湖泊作 为水资源、生物资源以及环境资源的重要载体, 是人类赖以生存和发展的重要基础,也是人类社会可持续发 展的基本保证 ${ }^{[1-3]}$. 湖泊生态系统健康评价, 符合可持续发展的思想, 有助于了解湖泊健康程度及变化趋势, 以供湖泊系统科学管理和生态修复 ${ }^{[4]}$.

国内外学者在评价方法和指标体系方面对湖泊生态系统健康评价都做了大量的研究. 目前湖泊生态系 统健康评价方法主要有生物检测法和多指标综合评价法 ${ }^{[3]}$. 蔡琨等 ${ }^{[5]}$ 借助生物检测法应用底栖动物完整性

* 国家重点研发计划项目(2017YFC0405602) 和国家自然科学基金创新研究群体科学基金项目 (51621096) 联合资 助. 2017-10-10 收稿;2018-01-09 收修改稿. 樊贤璐(1993 ), 女, 硕士研究生;E-mail : fanxianl26@ 126.com.

** 通信作者;E-mail:xuguob@ sina.com. 
指数进行太湖生态系统健康评价, 研究表明底栖动物完整性指数可以较为科学合理地进行生态系统健康评 价, 但单一生物检测法与环境因子之间的响应关系较弱, 不能有针对性地进行环境管理. 多指标综合评价法 涉及到不同尺度和不同的类群, 与环境因子关系密切且评价更具有综合性, 优势较为突出. 目前多指标综合 评价法主要有模糊综合评价法 ${ }^{[6]}$ 、系统动力模型法 ${ }^{[7]}$ 、人工神经网络法 ${ }^{[8]}$ 和投影寻踪法 ${ }^{[9]}$ 等. 这些评价方法 仅限于在指标体系构建中涵盖生态完整性和社会服务功能两方面指标, 最终输出结果为湖泊的总体健康状 况, 缺乏对生态完整性与社会服务功能相对独立又相互整合的研究, 难以直观地体现生态完整性和社会服 务功能两者间相互作用的对比关系. 本文借助协调发展度 ${ }^{[10-12]}$ 的理念, 将协调发展度引入湖泊健康评价中, 不仅可以反映湖泊生态系统整体发展水平和优劣形势, 还可以体现出发展过程中各内部影响要素之间相互 协同作用的程度,为湖泊生态系统科学管理提供依据.

目前湖泊生态系统健康评价指标体系有生态完整性指标体系 ${ }^{[13]}$ 、热力学指标体系 ${ }^{[14-15]}$ 和涵盖环境压力一 状态一响应的综合指标体系 ${ }^{[16]}$. 但对于已建立的指标体系只能针对某一特定生态系统, 在大量的指标中如 何高效地篮选出有代表性的指标构成研究区域的评价指标体系这一问题尚未解决, 缺乏统一指标体系框架. 本文统计 2005-2017 年间文献, 通过频度分析法建立指标体系, 形成湖泊生态系统指标体系统一框架, 为湖 泊健康评价体系提供参考.

\section{1 生态一社会服务功能协调发展度评价方法}

\section{1 协调发展度模型}

协调发展度模型通过将协调度和综合发展水平相结合的方式, 来反映系统协调发展程度, 是物理学中 容量耦合模型的发展与衍变. 协调是指系统之间或系统组成要素之间相互作用、互为辅助的良性协同关 系 ${ }^{[17]}$, 协调发展强调系统整体性、综合性的全面提升. 协调发展理论是可持续发展的基础, 可从理论上突破 区域社会经济发展的片面性,对区域发展中的各个组成要素起规划指引作用. 协调发展度用于衡量系统间 或系统内部要素间在发展过程中相互作用的协调程度 ${ }^{[18]}$. 目前, 协调发展度模型在社会经济领域中的应用 较为成熟, 李艳等 ${ }^{[10]}$ 、孙小娇等 ${ }^{[18]}$ 、王毅等 ${ }^{[19]}$ 和黄一绥 ${ }^{[20]}$ 学者分别以人口一环境、经济一环境为切人点探究 社会经济系统要素的协调发展规律, 研究尺度小到县级, 大到全国区域; 在倡导可持续发展的大环境下,协 调发展度模型越来越得到其他研究领域的重视.

在这里湖泊协调发展度是一个定量指标, 用以度量湖泊生态完整性和社会服务功能之间关系, 强调湖 泊生态系统内部影响要素相互配合, 共同发展 ${ }^{[20]}$, 旨在指导人们更有效地处理湖泊生态完整性和社会服务 功能之间的关系, 确保总体效益最大化.

\section{2 湖泊健康评价指标体系建立}

选取合适的评价指标是进行湖泊健康评价的关键, 本文从生态完整性和社会服务功能两方面出发, 运 用层次分析法, 采用目标层、准则层和指标层 3 级体系构建湖泊健康评价指标体系. 湖泊的生态完整性反映 湖泊生态系统的生物和生态环境各个方面的特性, 包括生物、物理和化学 3 个方面. 对湖泊生态完整性的研 究即对湖泊生态系统生物、物理和化学完整性参数的研究, 可从生物、地貌、水文、水质等方面构建指标体 系; 湖泊的社会服务功能是指湖泊为人类提供生态服务并满足人类社会发展合理要求的能力,包含供水、养 殖、发电、旅游休闲、气候调节等方面. 指标选取需遵循可测性、完备性、独立性、可比性、灵敏性及综合性原 则 ${ }^{[21]}$. 依据文献权威性和实效性检索文献, 统计国内外 2005-2017 年间核心及以上期刊有关湖泊健康的文 献 97 篇, 得到 88 个湖泊健康评价指标体系并梳理出 270 个指标. 各个指标按照水文水资源、物理结构、水 质、生物和社会服务功能划分并统计每个准则层的指标个数,依据指标表征的含义及隶属关系进行归纳整 合,计算整合后的指标在该准则层的采用频率. 依据频率高低结合指标选取原则确定出具有适用性强、代表 性高的关键指标.

鉴于湖泊结构、环境和功能的差异, 指标体系也有所不同. 本文将指标层分为共选指标和特性指标, 其 中共选指标是指湖泊健康评价指标中不受地域变化和时间变化影响、采用频率突出且适用于任一湖泊生态 系统的指标; 特性指标是指受流域地理条件、水文地质和社会经济等因素影响, 具有地域特点的指标. 结合 已有研究成果 ${ }^{[22-24]}$ 形成湖泊生态系统指标体系统一框架 (表 1). 针对一条特定湖泊, 需深人分析流域状况, 
选取湖泊特性指标,结合共选指标完成评价体系的构建.

表 1 湖泊健康评价指标体系

Tab.1 Index system of lake health assessment

\begin{tabular}{|c|c|c|c|c|c|}
\hline 目标层 & 准则层 & 共选指标 & 频率 & 特性指标 & 频率 \\
\hline \multirow[t]{22}{*}{ 湖泊健康 } & 水文水资源 $(\mathrm{HD})$ & 最低生态水位满足状况 & $23.12 \%$ & 水位波动 & $8.02 \%$ \\
\hline & & 人湖流量变异程度 & $17.71 \%$ & 允许的水位变幅 & $9.88 \%$ \\
\hline & 物理结构 (PF) & 河湖联通状况 & $18.63 \%$ & 每公里堤坝数 & $9.57 \%$ \\
\hline & & 湖泊萎缩状况 & $16.52 \%$ & 流域土地利用状况 & $10.21 \%$ \\
\hline & & 湖滨带状况 & $11.46 \%$ & 湖泊深度 & $7.98 \%$ \\
\hline & 水质 $(\mathrm{WQ})$ & 溶解氧水质状况 & $20.68 \%$ & PH 值 & $9.83 \%$ \\
\hline & & 耗养有机物污染状况 & $17.64 \%$ & 透明度 & $11.26 \%$ \\
\hline & & 富营养状况 & $21.37 \%$ & 高锰酸盐指数 & $8.62 \%$ \\
\hline & & & & 化学需氧量 & $9.91 \%$ \\
\hline & 生物 (AL) & 浮游植物数量 & $16.77 \%$ & 叶绿素 a & $7.76 \%$ \\
\hline & & 浮游动物生物损失指数 & $13.56 \%$ & 硅藻比例 & $5.11 \%$ \\
\hline & & 大型水生植物覆盖度 & $12.93 \%$ & 物种数量 & $6.62 \%$ \\
\hline & & 大型无脊椎动物完整性指数 & $14.85 \%$ & 总生物量 & $7.33 \%$ \\
\hline & & 鱼类生物完整性指数 & $11.29 \%$ & & \\
\hline & 社会服务功能 & 水功能区达标指数 & $21.22 \%$ & 人湖污染指数 & $8.58 \%$ \\
\hline & & & & 污水处理率 & $6.72 \%$ \\
\hline & & & & 水质净化功能 & $5.58 \%$ \\
\hline & & 水资源开发利用指数 & $17.37 \%$ & 灌溉保证率 & $4.83 \%$ \\
\hline & & & & 供水保证率 & $8.82 \%$ \\
\hline & & 防洪指数 & $14.75 \%$ & 调蓄洪水功能 & $6.05 \%$ \\
\hline & & 公众满意度指数 & $10.92 \%$ & 观光旅游功能 & $4.29 \%$ \\
\hline & & & & 景观舒适度 & $3.37 \%$ \\
\hline
\end{tabular}

\section{3 指标数据归一化}

原始数据的量纲和数量级不同, 本文采用极差法对数据进行标准化处理, 取值范围在 $0 \sim 1$ 之间.

$$
x_{i j}=\frac{x_{i j}^{*}-x_{\min }}{x_{\max }-x_{\min }}\left(x_{i j}^{*} \text { 为正向指标 }\right), x_{i j}=\frac{x_{\text {max }}-x_{i j}^{*}}{x_{\text {max }}-x_{\text {min }}}\left(x_{i j}^{*} \text { 为反向指标 }\right)
$$

式中, $x_{i j}$ 为标准化的值; $x_{i j}^{*}$ 为湖泊生态系统第 $j$ 个监测点第 $i$ 个评价指标的实测值; $x_{\max }$ 为该指标序列中的 最大值; $x_{\text {min }}$ 为该指标序列中的最小值.

\section{4 基于变异系数法和信息熵权法的组合赋权法确定权重}

1.4.1 变异系数法 变异系数法是直接利用各项指标所包含的信息,通过计算得到指标的权重, 是一种客观 赋权的方法. 在评价指标体系中, 指标取值差异越大的指标, 也就是越难以实现的指标, 这样的指标更能反 映被评价对象的差距,则赋分值越大 ${ }^{[18]}$, 变异系数及权重计算公式为 ${ }^{[25]}$ :

$$
V_{i}=\frac{\sigma_{i}}{\overline{x_{i}}}, \quad \alpha_{i}=\frac{V_{i}}{\sum_{i=1}^{n} V_{i}} \quad(i=1,2 、 \cdots, n)
$$

式中, $V_{i}$ 为第 $i$ 项指标的变异系数; $\sigma_{i}$ 为第 $i$ 项指标的标准差; $\overline{x_{i}}$ 为第 $i$ 项指标的平均值; $\alpha_{i}$ 为变异系数 权重.

1.4.2 摘权法 熵权法作为客观定权法可以反映指标数据隐含的信息, 熵越小, 熵权越大, 表示指标的差异性 越大,指标发展性更强; 反之, 指标熵越大, 熵权越小 ${ }^{[26]}$. 信息熵的公式为:

$$
S^{*}=-\frac{1}{\ln n} \sum_{i=1}^{n} \frac{x_{i j}}{x^{*}} \ln \frac{x_{i j}}{x^{*}}, \quad x^{*}=\sum_{i=1}^{n} x_{i j} \quad(i=1 、 2 、 \cdots, n ; j=1 、 2 、 \cdots 、 m)
$$


式中, $S^{*}$ 为第 $j$ 个指标的信息熵; $x^{*}$ 为所有水域第 $j$ 个指标之和.

熵权重公式为:

$$
\beta_{i}=\frac{1-S^{*}}{m-\sum_{j=1}^{m} S^{*}}
$$

式中, $\beta_{i}$ 为熵权重; $m$ 为指标数.

1.4 .3 组合赋权法 应用变异系数法既可以弥补熵权法计算所存在的均衡化缺陷, 又可以反映监测数据所带 有的信息性 ${ }^{[27]}$,其权重系数比单独利用一种计算方法更趋于合理,公式为:

$$
W=\lambda \cdot \beta_{i}+(1-\lambda) \alpha_{i}
$$

式中, $W$ 为几何平均赋权; $\beta_{i}$ 为熵权重; $\alpha_{i}$ 为变异系数法确定的权重; $\lambda$ 为偏好系数, 本文 $\lambda$ 取 0.5 .

\section{5 健康状况指数}

湖泊生态完整性用指标 $x_{1} 、 x_{2} 、 \cdots 、 x_{p}$ 来定量表征, 湖泊社会服务功能用指标 $y_{1} 、 y_{2} 、 \cdots 、 y_{m}$ 来定量表征, 湖 泊各监测点的生态完整性指数 $f(x)$ 和社会服务功能指数 $g(y)$ 可表达为:

$$
f(x)=\sum_{i=1}^{p} w_{i} x_{i}, g(y)=\sum_{j=1}^{m} w_{j} y_{j}
$$

式中, $w_{i}$ 和 $w_{j}$ 分别表示湖泊生态完整性和社会服务功能各指标的权重.

\section{6 系统协调发展度}

1.6.1 协调度 湖泊生态系统完整性指数 $f(x)$ 和社会服务功能指数 $g(y)$ 的值越大, $f(x)$ 与 $g(y)$ 的离差系数 越小, 则表明湖泊生态系统越健康. 两者之间的协调度可用下式计算 ${ }^{[11]}$ :

$$
\begin{gathered}
C=\left(1-C_{\mathrm{fg}}^{2}\right)^{k} \\
C_{\mathrm{fg}}=\sqrt{1-\frac{f(x) \cdot g(y)}{\left(\frac{f(x)+g(y)}{2}\right)^{2}}}
\end{gathered}
$$

式中, $C$ 为湖泊生态完整性 $f(x)$ 及其社会服务功能 $g(y)$ 的协调度; $C_{\mathrm{fg}}$ 为湖泊生态完整性 $f(x)$ 和社会服务功 能 $g(y)$ 系统间的离差系数; $k$ 为调节系数, 取值范围在 $2 \sim 5$ 之间, 这里取 $k=4$. 协调度 $C$ 随着离差系数 $C_{\mathrm{fg}}$ 的减小而增大, $C$ 值越大则表明湖泊生态系统内部影响要素协调性越高.

1.6.2 协调发展度 湖泊生态系统内部影响要素的协调度高可以反映出湖泊生态系统生态完整性和社会服 务功能两方面发展状况步调相似, 但是两者发展同步可能存在两者发展程度都较低的情况. 借助协调发展 度不仅可以体现生态完整性和社会服务功能的协调性, 还可以体现湖泊生态系统的发展能力, 公式为 ${ }^{[28]}$ :

$$
T=W_{i} \cdot f(x)+W_{j} \cdot g(y), D=\sqrt{C \cdot T}
$$

式中, $T$ 为监测点综合发展水平指数, 反映湖泊生态系统的健康; $W_{i}$ 和 $W_{j}$ 分别为湖泊生态系统完整的权重

和湖泊社会服务功能的权重, $W_{i}=\sum_{i=1}^{p} w_{i}, W_{j}=\sum_{j=1}^{m} w_{j} ; D$ 为协调发展度, 反映湖泊生态系统完整性与社会服 务功能系统间的协调发展状况.

1.6.3 总体协调发展度 湖泊生态系统数据来源通常由各个湖泊监测站提供, 通过湖泊总体的生态系统完整 性指数 $F(x)$ 和社会服务功能指数 $G(y)$ 得到总体协调发展度, 公式为 ${ }^{[29]}$ :

$$
F(x)=\sum_{i=1}^{N} \frac{f(x)_{i} \cdot S_{i}}{S}, G(y)=\sum_{j=1}^{N} \frac{g(y)_{j} \cdot S_{j}}{S}
$$

式中, $f(x)_{i}$ 和 $g(y)_{j}$ 分别为各监测点的生态完整性指数和社会服务功能指数; $S_{i}$ 为第 $i$ 个监测点所监控的 湖泊面积; $S_{j}$ 为第 $j$ 个监测点所监控的湖泊面积; $N$ 为湖泊内监测点的个数; $S$ 为湖泊总面积. 由 $F(x)$ 和 $G(y)$ 代人式 (6 9) 中, 得到湖泊总体协调度、总体综合发展水平指数和总体协调发展度.

\section{7 协调发展度评价等级及湖泊健康等级划分}

依据国家《地表水环境质量标准》(GB 3838-2002) ${ }^{[30]}$, 参考国内外湖泊健康评价标准等级和协调发展 度等级标准划分已有成果, 将湖泊综合发展水平指数 ${ }^{[31-32]}$ 和湖泊协调发展度 ${ }^{[12,18]}$ 划分为 5 个等级 $($ 表 2 ). 
表 2 湖泊健康等级划分及评价标准

Tab.2 Classification and evaluation criteria of lake health

\begin{tabular}{|c|c|c|c|c|c|}
\hline \multicolumn{3}{|c|}{ 湖泊综合发展水平 $T$} & \multicolumn{3}{|c|}{ 湖泊协调发展度 $D$} \\
\hline \multirow[t]{2}{*}{ 病态萎缩区间 } & $0 \sim 0.2$ & 病态 & 失调衰退区间 & $0 \sim 0.2$ & 严重失调 \\
\hline & $0.2 \sim 0.4$ & 不健康 & & $0.2 \sim 0.4$ & 中度失调 \\
\hline \multirow[t]{3}{*}{ 健康稳定区间 } & $0.4 \sim 0.6$ & 亚健康 & 协调发展区间 & $0.4 \sim 0.6$ & 临界协调 \\
\hline & $0.6 \sim 0.8$ & 健康 & & $0.6 \sim 0.8$ & 中级协调 \\
\hline & $0.8 \sim 1.0$ & 很健康 & & $0.8 \sim 1.0$ & 优质协调 \\
\hline
\end{tabular}

基于生态一社会服务功能协调发展度的湖泊健康评价方法给出了从湖泊综合发展水平和湖泊协调发 展度两方面度量湖泊生态系统健康水平的等级划分标准, 更全面地评价湖泊现状. 此外, 输出结果中包含生 态完整性指数、社会服务功能指数、协调度、综合发展水平指数和协调发展度. 这些结果的输出可更为直观 地整合湖泊生态系统生态和社会服务功能两方面的信息,分析其协调性和发展性. 同时,生态和社会服务功 能数字化、可视化结果更易于进行整合分析, 突出湖泊生态系统在协调发展中存在问题, 提出更具目标性和 方向性的建设重点.

湖泊因其地理位置、环境和功能等的差异,对生态完整性和社会服务功能有不同的要求. 对于人类干扰 较小的天然湖泊如高原湖泊, 其社会服务功能甚微, 有关社会服务功能的指标差异性极小, 相应权重小; 但 因其生态完整性优势突出, 仍可以得到较为良好的综合发展水平, 但是由于社会服务功能和生态完整性极 大的不协调,造成湖泊协调发展性较差.

\section{2 白洋淀生态环境与社会服务协调发展实证分析}

以白洋淀生态系统为研究对象,利用上述评价方法对其进行健康评价.

\section{1 研究区域概况}

白洋淀 $\left(38^{\circ} 43^{\prime} \sim 39^{\circ} 02^{\prime} \mathrm{N}, 115^{\circ} 38^{\prime} \sim 116^{\circ} 07^{\prime} \mathrm{E}\right)$ 是位于河北省保定市安新县境内的典型草型浅水湖泊. 淀区共 143 个淀泊, 水面面积约为 $150 \mathrm{~km}^{2[32]}$. 目前白洋淀存在的生态环境问题主要有: 人淀水量减小、水量 损失增大; 水体污染严重富营养化现象突出; 湖泊萎缩生态系统脆弱. 随着雄安新区的建设, 亟需对白洋淀 生态环境进行健康评价,下面基于协调发展度评价方法对白洋淀进行健康评价.

\section{2 数据来源}

参考《湖泊健康评估指标、标准与方法》 ${ }^{[33]}$, 结合白洋淀自身实际及海河流域重要水功能区管理,在白 洋淀布设监测断面 12 个, 白洋淀评估监测点示意如图 1 所示. 选取植物生长旺盛的 5 月和 8 月对白洋淀湖 滨带状况、水质和生物状况进行实地调研, 收集 2014 年白洋淀十方院水文站水位流量资料并以问卷的形式 进行公众满意度调查. 评估指标体系所含指标众多,为了将各指标值综合考虑, 对各指标监测值采取 “插值 评分”无量纲化处理, “插值评分”方法及参照标准引湖泊标准,该方法结合国家《地表水环境质量标准》 (GB3838-2002), 将评价指标划分为 $k$ 级, 每一级有对应的评分. 确定指标检测值所处的级别, 根据相邻级 别间的评分采用线性内插法,确定指标检测值对应的评分. 白洋淀各水域指标状况如表 3 所示.

\section{3 白洋淀健康评价指标体系及权重确定}

参考已建立的湖泊健康评价指标体系结合白洋淀区域特征, 完成白洋淀健康评价指标体系构建. 共选 指标由湖泊健康评价体系中全部共选指标构成; 白洋淀周围分布大量村庄, 产生的生活垃圾、生活污水及农 业面源污染等严重影响着水质; 由于白洋淀水源缺乏、围淀造田等因素, 湖泊萎缩严重; 此外, 近年来白洋淀 旅游业兴起, 旅游已经成为发展当地经济的重要项目. 综合考虑以上因素选取湖泊健康评价体系特性指标 中“人湖污染指数”、“流域土地利用状况” 和“景观舒适度”为特性指标, 形成白洋淀健康评价指标体系. 通 过基于信息熵权法和变异系数法的组合赋权法确定权重 (表 4). 
表 3 白洋淀各监测点指标评分

Tab.3 Index score of Lake Baiyangdian monitoring points

\begin{tabular}{|c|c|c|c|c|c|c|c|c|c|c|c|c|}
\hline 指标层 & 大张庄 & 留通 & 郭里口 & 王家寨 & $\begin{array}{l}\text { 光淀 } \\
\text { 张庄 }\end{array}$ & 菄林庄 & 圈头 & 采蒲台 & 端村 & 前塘 & 安新桥 & 关城 \\
\hline 最低生态水位满足状况 & 96.22 & 95.09 & 94.86 & 90.12 & 93.89 & 96.91 & 90.41 & 89.42 & 89.76 & 94.96 & 96.36 & 94.97 \\
\hline 人湖流量变异程度 & 0.55 & 0.73 & 0.46 & 0.37 & 0.63 & 0.64 & 0.19 & 0.66 & 0.09 & 0.89 & 0.62 & 0.67 \\
\hline 河湖联通状况 & 44.79 & 42.32 & 33.38 & 41.00 & 33.87 & 43.44 & 42.64 & 31.64 & 31.58 & 44.75 & 43.72 & 40.38 \\
\hline 湖泊萎缩状况 & 0.41 & 0.05 & 0.60 & 0.21 & 0.14 & 0.46 & 0.33 & 0.53 & 0.04 & 0.56 & 0.97 & 0.56 \\
\hline 湖滨带状况 & 97.50 & 92.50 & 95.00 & 87.50 & 96.30 & 97.50 & 91.30 & 92.50 & 96.30 & 85.00 & 91.30 & 91.30 \\
\hline 流域土地利用状况 & 69.42 & 66.65 & 71.49 & 63.97 & 72.57 & 60.40 & 74.27 & 66.05 & 74.61 & 74.20 & 69.71 & 79.21 \\
\hline 溶解氧水质状况 & 85.00 & 81.00 & 59.00 & 47.00 & 81.00 & 83.00 & 83.00 & 97.00 & 100.00 & 100.00 & 100.00 & 100.00 \\
\hline 耗氧有机物污染状况 & 33.00 & 41.00 & 46.00 & 44.00 & 42.00 & 47.00 & 40.00 & 41.00 & 21.00 & 48.00 & 17.00 & 19.00 \\
\hline 富营养状况 & 53.00 & 47.00 & 22.00 & 0.00 & 49.00 & 52.00 & 51.00 & 12.00 & 9.60 & 50.00 & 53.00 & 47.00 \\
\hline 浮游植物数量 & 24.30 & 0.00 & 30 & 20.80 & 0.00 & 30.80 & 10.00 & 0.00 & 19.40 & 0.00 & 48.90 & 0.00 \\
\hline 浮游动物生物损失指数 & 7.60 & 9.20 & 7.20 & 9.20 & 7.60 & 4.00 & 5.20 & 8.00 & 9.20 & 7.20 & 4.40 & 4.80 \\
\hline 大型水生植物覆盖度 & 100.00 & 100.00 & 95.00 & 95.00 & 95.00 & 100.00 & 90.00 & 100.00 & 100.00 & 91.00 & 90.00 & 80.00 \\
\hline 大型无脊椎动物完整性指数 & 52.00 & 37.00 & 17.00 & 22.00 & 22.00 & 25.00 & 23.00 & 34.00 & 30.00 & 43.00 & 66.00 & 100.00 \\
\hline 鱼类生物完整性指数 & 29.20 & 29.20 & 29.20 & 29.20 & 29.20 & 29.20 & 29.20 & 29.20 & 29.20 & 29.20 & 29.20 & 29.20 \\
\hline 水功能区达标指数 & 3.28 & 6.77 & 5.21 & 2.29 & 4.19 & 3.25 & 1.86 & 8.23 & 1.37 & 8.11 & 0.83 & 6.41 \\
\hline 人湖污染指数 & 42.22 & 52.60 & 54.49 & 44.65 & 49.22 & 59.60 & 45.69 & 42.77 & 45.64 & 54.55 & 52.36 & 42.54 \\
\hline 水资源开发利用指数 & 64.85 & 63.79 & 51.53 & 69.49 & 68.34 & 62.62 & 69.95 & 63.61 & 67.68 & 65.34 & 53.53 & 62.87 \\
\hline 防洪指数 & 94.36 & 95.37 & 91.12 & 95.11 & 94.87 & 92.41 & 92.59 & 95.38 & 91.03 & 90.66 & 90.01 & 91.72 \\
\hline 公众满意度指数 & 67.84 & 67.03 & 65.60 & 66.20 & 65.31 & 62.30 & 61.58 & 64.46 & 63.50 & 60.18 & 61.87 & 60.92 \\
\hline 景观舒适度 & 73.21 & 77.98 & 77.65 & 73.26 & 78.31 & 78.30 & 75.26 & 76.03 & 77.32 & 73.94 & 79.16 & 78.82 \\
\hline
\end{tabular}

表 4 白洋淀健康评估指标体系

Tab.4 Index system of Lake Baiyangdian health assessment

\begin{tabular}{|c|c|c|c|c|c|c|c|}
\hline 目标层 & 亚层 & 权重 & 准则层 & 指标层 & $\begin{array}{l}\text { 变异系数 } \\
\text { 权重 } \alpha_{i}\end{array}$ & $\begin{array}{c}\text { 熵权重 } \\
\beta_{i}\end{array}$ & $\begin{array}{l}\text { 综合 } \\
\text { 赋权 } W\end{array}$ \\
\hline \multirow[t]{20}{*}{ 白洋淀 } & 生态完整性 & 0.655 & 水文水资源 & 最低生态水位满足状况 & 0.045 & 0.039 & 0.042 \\
\hline & & & & 人湖流量变异程度 & 0.057 & 0.061 & 0.059 \\
\hline & & & 物理结构 & 河湖联通状况 & 0.051 & 0.039 & 0.045 \\
\hline & & & & 湖泊萎缩状况 & 0.036 & 0.051 & 0.044 \\
\hline & & & & 湖滨带状况 & 0.021 & 0.015 & 0.018 \\
\hline & & & & 流域土地利用状况 & 0.056 & 0.032 & 0.044 \\
\hline & & & 水质 & 溶解氧水质状况 & 0.047 & 0.036 & 0.042 \\
\hline & & & & 耗氧有机物污染状况 & 0.038 & 0.048 & 0.043 \\
\hline & & & & 富营养状况 & 0.050 & 0.063 & 0.057 \\
\hline & & & 生物 & 浮游植物数量 & 0.027 & 0.071 & 0.049 \\
\hline & & & & 浮游动物生物损失指数 & 0.021 & 0.061 & 0.041 \\
\hline & & & & 大型水生植物覆盖度 & 0.019 & 0.103 & 0.061 \\
\hline & & & & 大型无脊椎动物完整性指数 & 0.074 & 0.044 & 0.059 \\
\hline & & & & 鱼类生物完整性指数 & 0.066 & 0.039 & 0.053 \\
\hline & 社会服务 & 0.345 & 社会服务功能 & 水功能区达标指数 & 0.107 & 0.018 & 0.063 \\
\hline & & & & 人湖污染指数 & 0.028 & 0.069 & 0.049 \\
\hline & & & & 水资源开发利用指数 & 0.033 & 0.072 & 0.053 \\
\hline & & & & 防洪指数 & 0.102 & 0.041 & 0.072 \\
\hline & & & & 公众满意度指数 & 0.075 & 0.037 & 0.056 \\
\hline & & & & 景观舒适度 & 0.047 & 0.061 & 0.054 \\
\hline
\end{tabular}




\section{4 评价结果}

将监测点数据代人式 $(1 \sim 10)$, 计算各监测点的生态完整性指数、社会服务功能指数和协调发展度等数 据,并依据健康评价标准确定各水域的健康等级,计算结果见图 1、表 5 和图 2.

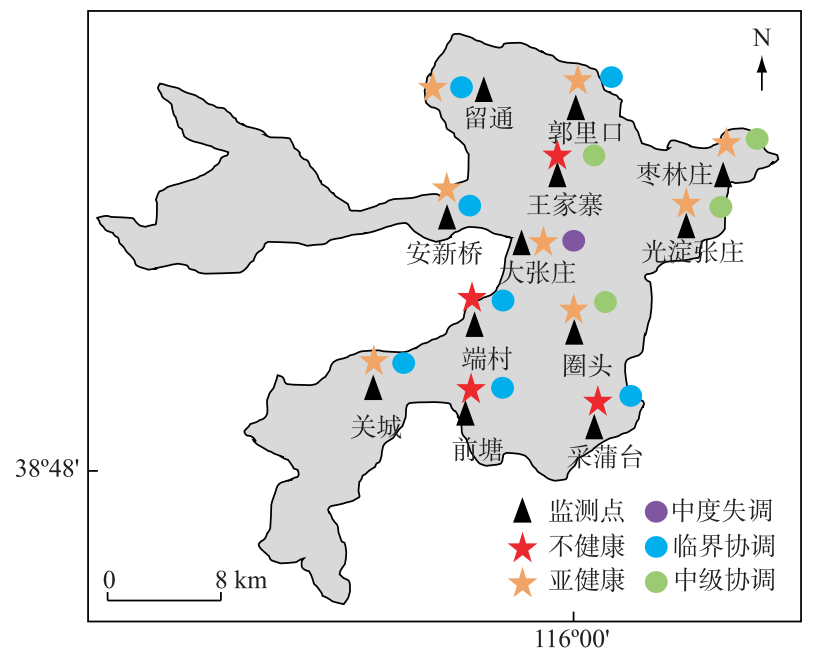

图 1 白洋淀各监测点综合评价指数与协调度状况

Fig. 1 Comprehensive evaluation status and coordination degree of Lake Baiyangdian monitoring points

表 5 白洋淀生态完整性和社会服务功能两系统的协调发展模型计算

Tab.5 Model calculation of ecological integrity and social service function of Lake Baiyangdian

\begin{tabular}{|c|c|c|c|c|c|c|c|}
\hline 监测点 & $f(x)$ & $g(y)$ & C & $T$ & $D$ & 健康等级 & 协调发展等级 \\
\hline 大张庄 & 0.482 & 0.364 & 0.925 & 0.447 & 0.643 & 亚健康 & 中级协调 \\
\hline 留通 & 0.487 & 0.292 & 0.771 & 0.428 & 0.575 & 亚健康 & 临界协调 \\
\hline 郭里口 & 0.476 & 0.274 & 0.739 & 0.416 & 0.554 & 亚健康 & 临界协调 \\
\hline 王家寨 & 0.377 & 0.137 & 0.373 & 0.305 & 0.337 & 不健康 & 中度失调 \\
\hline 光淀张庄 & 0.465 & 0.359 & 0.936 & 0.433 & 0.637 & 亚健康 & 中级协调 \\
\hline 菄林庄 & 0.474 & 0.356 & 0.921 & 0.439 & 0.636 & 亚健康 & 中级协调 \\
\hline 圈头 & 0.411 & 0.370 & 0.984 & 0.399 & 0.632 & 亚健康 & 中级协调 \\
\hline 采蒲台 & 0.346 & 0.251 & 0.903 & 0.317 & 0.535 & 不健康 & 临界协调 \\
\hline 端村 & 0.245 & 0.188 & 0.932 & 0.228 & 0.461 & 不健康 & 临界协调 \\
\hline 前塘 & 0.393 & 0.280 & 0.890 & 0.359 & 0.556 & 不健康 & 临界协调 \\
\hline 安新桥 & 0.533 & 0.272 & 0.643 & 0.455 & 0.541 & 亚健康 & 临界协调 \\
\hline 关城 & 0.480 & 0.219 & 0.548 & 0.401 & 0.469 & 亚健康 & 临界协调 \\
\hline 急体 & & $F(x)$ & $\begin{array}{r}G(x) \\
\text { 湖沙 }\end{array}$ & , $C_{\text {总态 }}$ & $\begin{array}{l}8, T_{\text {总 }}= \\
\text { 界协调 }\end{array}$ & $D_{\text {总 }}=0$. & \\
\hline
\end{tabular}

1) 12 个监测点中除王家寨、采蒲台、端村和前塘属于不健康状态, 其余监测点均属于亚健康状态. 白洋淀 生态系统综合健康指数总体偏低,健康受损严重. 白洋淀东北方向水域健康水平相对较好, 中部王家寨以及西 南方向圈头、采蒲台和前塘村庄密集,生活污水排放及水产养殖活动使水域健康受到极大破坏,富营养化问题 严重,综合发展指数低,处于不健康状态; 远离人口密集区的关城、留通及安新桥等监测点污染相对较小.

2) 白洋淀东北方向東林庄、大张庄、光淀张庄和圈头处于中级协调状态,生态完整性和社会服务功能较 为协调; 王家寨因生态严重受损出现中度失调衰退状况, 生态健康亟待整治, 同时为后期社会服务建设奠定 基础; 各监测点均出现社会服务功能指数小于生态完整性指数, 即 $g(y)<f(x)$ 的情况, 白洋淀生态系统社会 


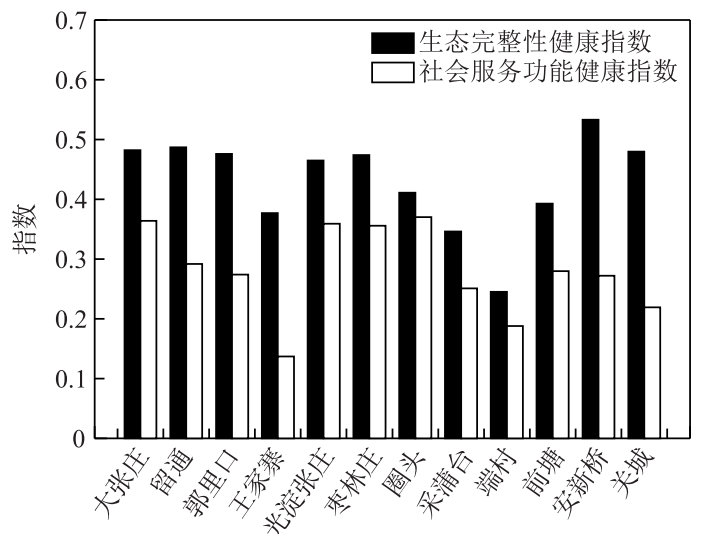

监测点

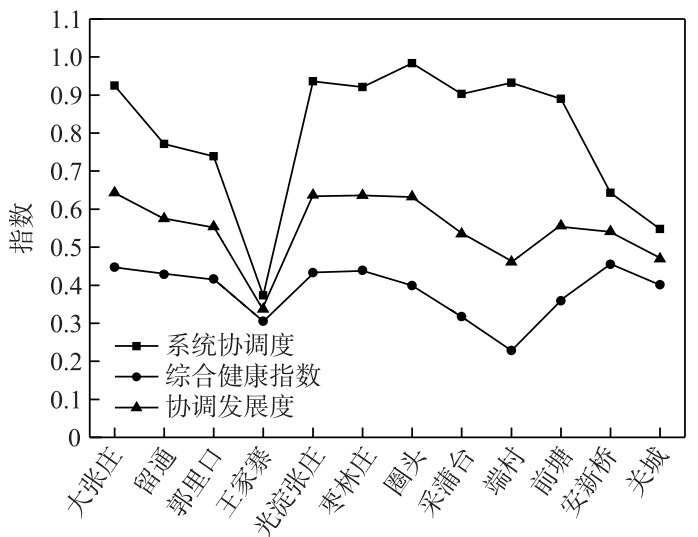

监测点

图 2 白洋淀各监测点健康状况

Fig. 2 Health status of monitoring points in Lake Baiyangdian

服务功能发展受限. 目前生态完整性可支撑更好的社会服务功能, 湖泊管理应合理推进湖泊水功能区达标 指数及景观舒适度等建设; 此外, 由图 2 可以看出, 白洋淀各监测点的协调度 $C$ 较高, 协调发展度 $D$ 较低, 表 明生态完整性与社会服务功能两者在同步较低水平发展, 加强社会服务功能建设促进两者协调性的同时, 整体提高生态完整性与社会服务功能发展水平是白洋淀建设的关键.

3) 白洋淀总体处于不健康病态萎缩状态, 临界协调发展. 分析处理各准则层数据得到, 白洋淀水资源危 机, 水量严重不足,故而导致自身净化能力减弱; 水污染严重, 水质恶化, 污染源多, 水上种植和养殖业等经 济活动加速白洋淀的污染; 湖面面积萎缩、围淀造田、围淀养鱼及频繁断流等原因造成白洋淀年内水面面积 波动大, 常有干淀威胁.

\section{5 发展保护建议}

1) 保证生态需水. 白洋淀本身存在水量严重不足的情况, 而未来雄安新区的建设必然会加大对白洋淀 生态需水的要求, 解决生态需水问题是白洋淀生态恢复最关键的一步. 一方面可加强上游水土保持和绿化 工作并有效控制上游水量使用, 合理调度水资源; 另一方面减少人工干扰, 如 “人退湖进”、建设相应的垃圾 长效处理机制等措施保护水源, 改善湖泊萎缩状况.

2)减少污染, 提高水质状况. 调整产业结构, 淀区居民需弱化水产养殖, 减少养殖业污染; 在建的雄安新 区需严格限制高污企业,提高企业污水处理能力,防止水质恶化;生活污水统一排放,避免生活污水人淀.

3) 提高社会服务功能水平. 目前评估结果中监测点均出现社会服务功能指数小于生态完整性指数的情 况, 将来随着新区建设发展, 公众对白洋淀社会服务功能的要求会不断增加. 需大力推进公众满意度和景观 舒适度建设,提高社会服务功能水平, 促进白洋淀生态系统协调发展.

\section{3 结论}

1) 建立基于生态一社会服务功能协调发展度的湖泊生态系统健康评价模型, 以湖泊综合健康指数和协 调发展度来衡量湖泊健康, 并提出相应的湖泊健康等级标准. 协调发展度模型既可以对某一个监测区域健 康水平进行评价也可以得到生态系统总体的健康水平, 具有计算简单、适用性强的特点. 此外, 该模型可将 湖泊生态完整性和社会服务功能两个不同属性结合, 以协调和发展的角度对湖泊健康进行评价, 符合可持 续发展的思想; 通过生物完整性指数与社会服务功能指数的对比可以得出湖泊今后建设重点, 为湖泊管理 者提供建议.

2) 构建湖泊生态系统健康评价指标体系, 形成统一框架. 针对某一湖泊可结合区域特征选取个性指标 即可制定出湖泊健康评价指标体系, 便于高效笁选指标的同时扩大指标体系适用范围, 为湖泊生态系统健 
康评价提供参考.

3) 以白洋淀监测点为例进行实例研究,白洋淀 12 个监测点计算结果显示: 白洋淀整体处于不健康病态 萎缩状态, 生态完整性和社会服务功能协调发展度处于临界协调发展状态. 白洋淀生态受损, 社会服务功能 不适配当前的生态水平. 雄安新区的建设, 对白洋淀生态和社会服务功能都提出了更高的要求, 白洋淀需保 证生态需水, 合理调度上游水资源, 改善湖泊萎缩状况; 减少污染, 提高水质; 在此基础上, 不断推进社会服 务功能建设,促进生态和社会服务功能协调发展.

\section{4 参考文献}

[ 1 ] Xu FL, Tao S, Dawson RW et al. Lake ecosystem health assessment: indicators and methods. Water Research, 2001,35 (13) : 3157-3167.

[ 2 ] Wu YW, Li YJ, Zhang LY et al. Assessment of lakes ecosystem health based on objective and subjective weighting combined with fuzzy comprehensive evaluation. J Lake Sci, 2017, 29( 5) : 1091-1102. DOI: 10.18307/2017.0507. [吴易雯, 李莹杰, 张列宇等. 基于主客观赋权模糊综合评价法的湖泊水生态系统健康评价. 湖泊科学, 2017, 29(5): 1091-1102.]

[ 3 ] Li B, Yang GS, Wan RR. Progress on evaluation methods of lake ecosystem health. Advances in Science and Technology of Water Resources, 2014, 34(6) : 98-106. [李冰, 杨桂山, 万荣荣. 湖泊生态系统健康评价方法研究进展. 水利水电 科技进展, 2014, 34(6): 98-106.]

[ 4 ] Ma KM, Kong HM, Guan WB et al. Ecosystem health assessment: methods and directions. Acta Ecologica Sinica, 2001, 21(12) : 2106-2116. [马克明, 孔红梅, 关文涁等. 生态系统健康评价: 方法与方向. 生态学报, 2001, 21(12) : 2106-2116. ]

[ 5 ] Cai K, Zhang J, Xu ZA et al. Application of a benthic index of biotic integrity for the ecosystem health assessment of Lake Taihu. J Lake Sci, 2014, 26(1): 74-82. DOI: 10.18307/2014.0109. [蔡琨, 张杰, 徐兆安等. 应用底栖动物完整性 指数评价太湖生态健康. 湖泊科学, 2014, 26(1): 74-82.]

[ 6 ] Li R, Zou Z, An Y. Water quality assessment in Qu River based on fuzzy water pollution index method. Journal of Environmental Sciences, 2016, 50(12): 87-92.

[ 7 ] Mooij WM, Trolle D, Jeppesen E et al. Challenges and opportunities for integrating lake ecosystem modelling approaches. Aquatic Ecology, 2010, 44(3) : 633-667.

[ 8 ] Mo MH, Wang XL, Wu HJ et al. Ecosystem health assessment of Honghu Lake Wetland of China using artificial neural network approach. Chinese Geographical Science, 2009, 19(4) : 349-356.

[ 9 ] Xue LQ, Zhu YZ, Wang SQ et al. Lake ecosystem health assessment based on projection pursuit. Water Resources Protection, 2016, (2) : 67-72. [薛联青, 朱祎真, 王思琪等. 基于投影寻踪的湖泊生态健康评价. 水资源保护, 2016, (2) : 67-72.]

[10] Li Y, Zhang ZX, Wu YX et al. Study and application of evaluation method of coordinated development of economy-environment system. System Eng Theor Prac, 2003, 23(5) : 54-58. [李艳, 曾珍香, 武优西等. 经济-环境系统协调发展评 价方法研究及应用. 系统工程理论与实践, 2003, 23(5): 54-58.]

[11] Zhao LN, Xu GB. Discrimination of channel patterns based on coordinated developmental degree. Journal of Sediment Research, 2013, (5) : 10-14. [赵丽娜, 徐国宾. 基于协调发展度的冲积河流的河型判别式. 泥沙研究, 2013, (5): 10-14.]

[12] Hu W, Dou L, Wu W et al. Evaluation of coordinated development degree between economy and environment in Gansu. Chinese Agricultural Science Bulletin, 2010.

[13] Brousseau CM, Randall RG, Hoyle JA et al. Fish community indices of ecosystem health: How does the Bay of Quinte compare to other coastal sites in Lake Ontario. Aquatic Ecosystem Health \& Management, 2011, 14(1) : 75-84.

[14] Jørgensen SE. Application of holistic thermodynamic indicators. Ecological Indicators, 2006, 6( 1) : 24-29.

[15] Xu GB, Ren W, Guo SY et al. Analyses on the development of lake complex ecosystem health based on entropy theory. China Environmental Science, 2017, 37(2) : 795-800. [徐国宾, 任旺, 郭书英等. 基于熵理论的湖泊生态系统健康 发展评估. 中国环境科学, 2017, 37(2): 795-800.]

[16] Zhang F, Zhang J, Wu R et al. Ecosystem health assessment based on DPSIRM framework and health distance model in Nansi Lake, China. Stochastic Environmental Research \& Risk Assessment, 2016, 30(4) : 1235-1247. 
[17] Munda G. “Measuring Sustainability” : A Multi-Criterion Framework. Environment Development \& Sustainability, 2005 , 7 (1) : 117-134.

[18] Sun XQ, Zhang DJ. Analysis on urban human settlement environment and economy coordination development degree in Shanxi Province based on CDM-GIS. Journal of Hebei Normal University: Natural Sciences, 2016, 40(5): 447-455. [孙 小娇, 张杜鹃. 基于 CDM-GIS 的山西省城市人居环境与经济协调发展度探析. 河北师范大学学报: 自然科学版, 2016, 40(5): 447-455.]

[19] Wang Y, Ding ZS, Yu MJ et al. Quantitative analysis of the coordination relation between modern service industry and urbanization based on coupling model: A case study of Changshu. Geogr Res, 2015, 34(1) : 97-108. DOI: 10.11821/ dlyj201501009. [王毅, 丁正山, 余茂军等. 基于耦合模型的现代服务业与城市化协调关系量化分析一一江苏省 常熟市为例. 地理研究, 2015, 34(1): 97-108.]

[20] Huang YS. Assessment and analysis on the harmony development degree between environment and economy in Fuzhou city. Environment Science and Management, 2008, 33(12): 44-47. [黄一绥. 福州市环境与经济协调发展度评价与分析. 环境科学与管理, 2008, 33(12): 44-47.]

[21] Lu ZJ, Pei HP, Wang Y et al. Preliminary exploration of ecosystem health assessment for Lake West. J Lake Sci, 2008, 20 (6) : 802-805. DOI: 10.18307/2008.0601. [卢志娟, 裴洪平, 汪勇. 西湖生态系统健康评价初探. 湖泊科学, 2008, 20(6) : 802-805.]

[22] Ren L, Yang JY, Xiang XY et al. Evaluation index system for lake ecosystem health. Journal of Hohai University: Natural Sciences, 2012, 40(1) : 100-103. [任黎, 杨金艳, 相欣奕. 湖泊生态系统健康评价指标体系. 河海大学学报: 自然 科学版, 2012, 40(1): 100-103.]

[23] Liu J, Wang W, Li CL. Study evolution of ecosystem health. Research of Environmental Sciences, 2002, 15(1) : 41-44.

[24] Xia JH, Yan ZM, Jiang CF. Study on comprehensive evaluation index system of riparian ecosystem. Adv Water Sci, 2005, (3) : 345-348. [夏继红, 严忠民, 蒋传丰. 河岸带生态系统综合评价指标体系研究. 水科学进展, 2005, (3): 345-348.]

[25] Zhao W, Lin J, Wang SF et al. Influence of human activities on groundwater environment based on coefficient variation method. Environmental Science, 2013, 34(4) : 1277-1283. DOI:10.13227/j.hjkx.201 -3.04.040. [赵微, 林健, 王树芳 等. 变异系数法评价人类活动对地下水环境的影响. 环境科学, 2013, 34(4) : 1277-1283.]

[26] Ba YE, Guo JS, Lu SY et al. Assessing ecological health of open water region from Bostenhu Lake during last 20 years. China Environmental Science, 2013, 33(3) : 503-507. [巴雅尔, 郭家盛, 卢少勇等. 博斯腾湖大湖湖区近 20 年生态 健康状况评价. 中国环境科学, 2013, 33(3): 503-507.]

[27] Jiang J. Fuzzy comprehensive evaluation model based on the combination weighting method of entropy weight and variation coefficient [Dissertation]. Beijing: Capital Normal University, 2011. [姜君. 基于熵权与变异系数组合赋权法的模糊 综合评价模型 [学位论文]. 北京: 首都师范大学, 2011.]

[28] Li Q, Su Y, Pei Y. Research on coupling coordination degree model between upstream and downstream enterprises//Information Management, Innovation Management and Industrial Engineering, 2008. ICIII'08. International Conference on. IEEE, 2008, 2: 172-175.

[29] Zhai J, Xu GB, Guo SY et al. Research on river health assessment method based on coordinated development degree. Journal of Hydraulic Engineering, 2016, 47(11) : 1465-1471. [翟晶, 徐国宾, 郭书英等. 基于协调发展度的河流健康评 价方法研究. 水利学报, 2016, 47(11): 1465-1471.]

[30］ GB 3838-2002. Environmental quality standard of surface Water, P. R China. [ GB 3838-2002. 中华人民共和国地表 水环境质量标准.]

[31] Zhang F, Yang J, Xi JC et al. Ecosystem health assessment of Nansihu Lake based on DPSIRM and health distance model. Resources Science, 2014, 36(4): 831-839. [张峰, 杨俊, 席建超等. 基于 DPSIRM 健康距离法的南四湖湖泊生态系 统健康评价. 资源科学, 2014, 36(4): 831-839.]

[32] Zhang LL, Liu JL, Yang ZF et al. Integrated ecosystem health assessment of a macrophyte-dominated lake. Ecological Modelling, 2013, 252(1): 141-152.

[33] Water Resources, Ministry of Water Resources. Index, standard and method of Lake health assessment (Pilot work use). Beijing, 2011. [水利部水资源司. 湖泊健康评估指标、标准与方法(试点工作用). 北京, 2011.] 